\title{
Ultrasonic spray pyrolysis technique to generate a solar absorber coating of $\mathrm{Mn}$-doped $\alpha-\mathrm{Fe}_{2} \mathrm{O}_{3}$
}

\author{
Carlos David Hernández-Pérez ${ }^{1}$, Enrique Barrera-Calva ${ }^{1, *}$, Federico González $^{1}$, and Victor Rentería Tapia ${ }^{2}$ \\ ${ }^{1}$ Universidad Autónoma Metropolitana - Iztapalapa. Av. San Rafael Atlixco No. 186, Col. Vicentina, C.P. 09340. Alcaldía \\ Iztapalapa, CDMX, México \\ ${ }^{2}$ Universidad de Guadalajara, Ameca Km. 45.5, C.P. 46600, Ameca, Jalisco, México
}

Received: 23 November 2020 / Received in final form: 7 February 2021 / Accepted: 8 February 2021

\begin{abstract}
Today, even though exist a Titanium Nitride Oxide, $\mathrm{TiNO}_{\mathrm{X}}$, a very good commercial solar absorber, the efforts to develop new and better solar absorbers like $\mathrm{TiNO}_{\mathrm{X}}$ are continuing in several laboratories all over the world. In this article, we used the ultrasonic spray pyrolysis technique to prepare manganese, Mn, Mn-doped $\alpha-\mathrm{Fe}_{2} \mathrm{O}_{3}$ dark thin films deposited on titanium substrates. The results of an analysis of the solar absorptance and thermal emittance of these films are also presented here; the optical properties depend of the proportions of Mn and iron, Fe, in the spray solution and of the deposit temperature. The best solar absorptance (0.94) and thermal emittance (0.07) values of the films prepared at $600{ }^{\circ} \mathrm{C}$ for iron and manganese ion with concentrations of 0.0015 and $0.0035 \mathrm{~mol} / \mathrm{l}$, respectively, are comparable with the optical properties of the Titanium Nitride oxide, $\mathrm{TiNO}_{\mathrm{X}}$, a very common commercial solar absorber used as an efficient coating for flat plate solar collectors industry.
\end{abstract}

\section{Introduction}

The global demand for energy has increased over time, and solar energy shows promise to significantly contribute to fulfilling current annual energy world demand $(630 \mathrm{EJ} / \mathrm{yr})$. Extensive research is actually being carried out on various materials that would allow them to be utilized in efficient solar-energy technology and take advantage of this energy source on an industrial scale [1-3]. In particular, the solar selective absorber coatings exhibit high solar absorptance in the UV-vis region and low infrared emittance, ideal conditions to achieve high efficiency in photo-thermal energy conversion [2].

Our topic of research is related to solar absorber materials, which must fulfill high standards of solar absorptance and thermal emittance. This type of material must also be non-toxic, abundant in nature, and stable to a high energy flux and temperature. An example of this type of reference material is TiNOx, which reachs a solar absorptance of 0.95 and an emittance of the order of 0.06 [3].

The basic principle of the conversion of solar energy to thermal occurs when solar radiation reaches the surface,

\footnotetext{
* e-mail: ebc@xanum.uam.mx
}

part of it will be absorbed, thus increasing the temperature and causing emission of infrared radiation from the surface of the material [1]. Figure 1 shows the two significant radiation ranges for this conversion: Solar from 0.3 to $2.5 \mu \mathrm{m}$ (part of ultraviolet, visible and near infrared) and infrared from 2.5 to $25 \mu \mathrm{m}$ (black body spectrum). Around $200^{\circ} \mathrm{C}$ there is a slight overlap of the two ranges, above $200^{\circ} \mathrm{C}$ the overlap is already considered a disadvantage due to the energy losses of the system. For medium temperature solar thermal applications, the working temperature of the device is less than $100{ }^{\circ} \mathrm{C}[1,2]$, hence this phenomenon became the subject of study from the year 1955 when Tabor introduced the use of surfaces spectral selective for solar collectors, considering a surface with optical properties that will take advantage of this phenomenon [3].

Various laboratories around the world continue to seek to obtain selective absorbent materials similar to or better than the classic TiNOx selective coating, by means of alternative techniques that represent an advantage in terms of costs or as a selective solar material. In this work we show the results, the chemical synthesis, the structural characterization and the optical properties of a coating based on Mn-doped iron oxide and applied on titanium substrates. (Mn-doped Hematite $\alpha-\mathrm{Fe}_{2} \mathrm{O}_{3}$ ), have been prepared and used for several application, one of the most recent was developed for Yuan et al. [4], who prepared this 


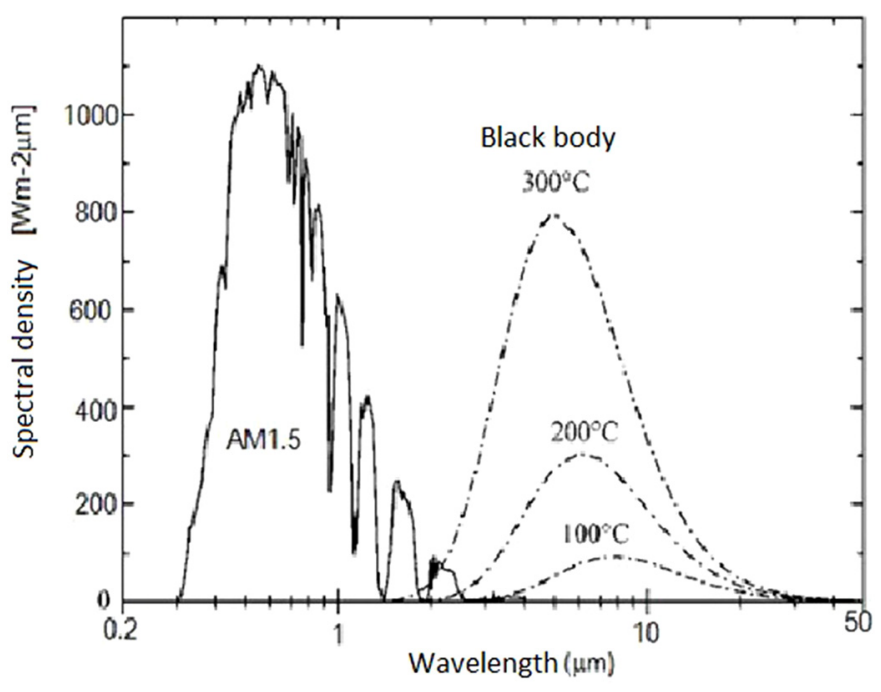

Fig. 1. Solar hemispherical spectral irradiance for AM1.5 (zenith angle $48.19^{\circ}$ ). Taken from the terrestrial reference spectrum for the American Society's photovoltaic technology performance evaluation.

system through the combination of laser ablation in liquid and hydrothermal treatment techniques, obtaining faceted Mn-doped $\alpha-\mathrm{Fe}_{2} \mathrm{O}_{3}$ nanocrystals (NCs). Electrochemical stripping tests revealed that this compound show a facetdependent adsorption ability toward $\mathrm{Pb}(\mathrm{II}), \mathrm{Cd}(\mathrm{II})$ and $\mathrm{Hg}$ (II) heavy-metal ions, which could be very useful technique to clean environment.

It must be recognized that in the most specialized laboratories in the synthesis of selective material, this type of research is still continued with different materials and different preparation techniques to try to equalize the properties of $\mathrm{TiNO}_{\mathrm{x}}$ or reduce its manufacturing costs. An example of these efforts is the development of selective material based on multi-walled carbon nanotube (MWCNT) solar absorbers on aluminum substrates that have been prepared by electrophoresis [5]. The MWCNT absorbers exhibit a good spectral selectivity over the visible and infrared wavelengths. However, to further enhance the solar absorption, an anti-reflection coating made from porous silica was spin-coated on top of MWCNT solar absorbers.

In this case, the Mn-doped $\alpha-\mathrm{Fe}_{2} \mathrm{O}_{3}$ system, synthesized and prepared by means of the ultrasonic spray technique, which provides very thin coatings, less than one micron, compact and of low roughness, which leads to obtainment of dark materials with good solar optical properties. These materials, could be absorber materials with potentially similar properties to $\mathrm{TiNO}_{\mathrm{x}}$. Hematite is an n-type semiconductor with a closed-package hexagonal crystal structure, having a high corrosion resistance and a cheap manufacturing cost [6]. This material has a band gap of $2.2 \mathrm{eV}$ located in the visible region of the solar spectrum, allowing the material, at least, to take advantage of almost the half of the incident solar radiation. As reported in [7], iron oxide's properties can be altered varying certain parameters, such as extrinsic defects and/or doping. Another advantage of this material is the diversity of preparation methods to synthesize $\mathrm{Fe}_{2} \mathrm{O}_{3}$. Several techniques, such as sputtering [8], sol-gel [9,10], spray pyrolysis [11,12], electrodeposition [13], hydrothermal technique [14], and pulsed laser evaporation [15], have been useful for this purpose.

A previous study has shown that $\mathrm{Mn}$ is an excellent option for doping $\mathrm{Fe}_{2} \mathrm{O}_{3}$ [16] Due to its position in the periodic table, the atomic radii of the $\mathrm{Fe}^{3+}$ and $\mathrm{Mn}^{2+}$ ions are similar to each other, implying that there will be no significant distortion of the host lattice. Solutions including these two ions would obey the Hume-Rothery Rules [17]. On the other hand, recent reports show that $\mathrm{Mn}$ is an excellent solar absorber because it maximizes the absorption of UV-VIS radiation [18]. In other example, it is essential to know the UV-Vis excitation bands in the emission properties of $\mathrm{Mn}^{2+}$ [19]. The excited states can be quadruplets and doublets of the Mn associated with prohibited transitions of spin [20].

Various physical and chemical techniques to obtain Mn-doped $\alpha-\mathrm{Fe}_{2} \mathrm{O}_{3}$ films have been developed. In particular, the ultrasonic spray pyrolysis is a physicochemical technique, Figure 2 which uses precursor salts in a solution in order to deposit thin films on substrates [21]. It is stands out from others because it does not require expensive accessories or a specific atmosphere to synthesize the materials. One of the main advantage of the ultrasonic spray pyrolysis are that the end material is obtained in film form with high adhesion, chemical stability that yield higher-density, mono and multilayer films. This technique, Figure 2. has proved successful in obtaining materials used in solar cells and semiconductors $[22,23]$, and now we propose its application in fabrication of solar selective coatings, that requires a little more thicker films with a surface roughness similar to the wavelength solar incident.

Today, there is a paucity of published reports on how to obtain Mn-doped hematite $\left(\alpha-\mathrm{Fe}_{2} \mathrm{O}_{3}\right)$ films for use as solar absorber. Previous research on this topic suggests that these materials could be excellent coatings to be utilized as good solar selective absorbers $[2,3]$.

The purpose of this work is related to develop of a solar absorber materials, which must fulfill high standards of solar absorptance and thermal emittance. This type of material must also be non-toxic, abundant in nature, and stable to a high energy flux and temperature. An example of this type of solar reference material is $\mathrm{TiNO}_{\mathrm{x}}$, which reachs a solar absorptance of 0.95 and an emittance of the order of 0.06. Our main objective is prepare and evaluate a solar absorber thin film of Mn-doped $\alpha-\mathrm{Fe}_{2} \mathrm{O}_{3}$ and on titanium substrate synthesized by the ultrasonic spray pyrolysis technique, having similar optical properties that the reference material. We describe the preparation method, the X-ray diffraction analysis, XRD, the solar optical properties and also the surface profile studies that tell us about thin film thickness and its surface roughness.

\section{Material and methods}

The substrates used for depositing the film material through the pyrolytic reaction were high purity titanium sheets $(99.9 \%)$ cut into $2 \times 2 \mathrm{~cm}^{2}$ samples. The substrates 


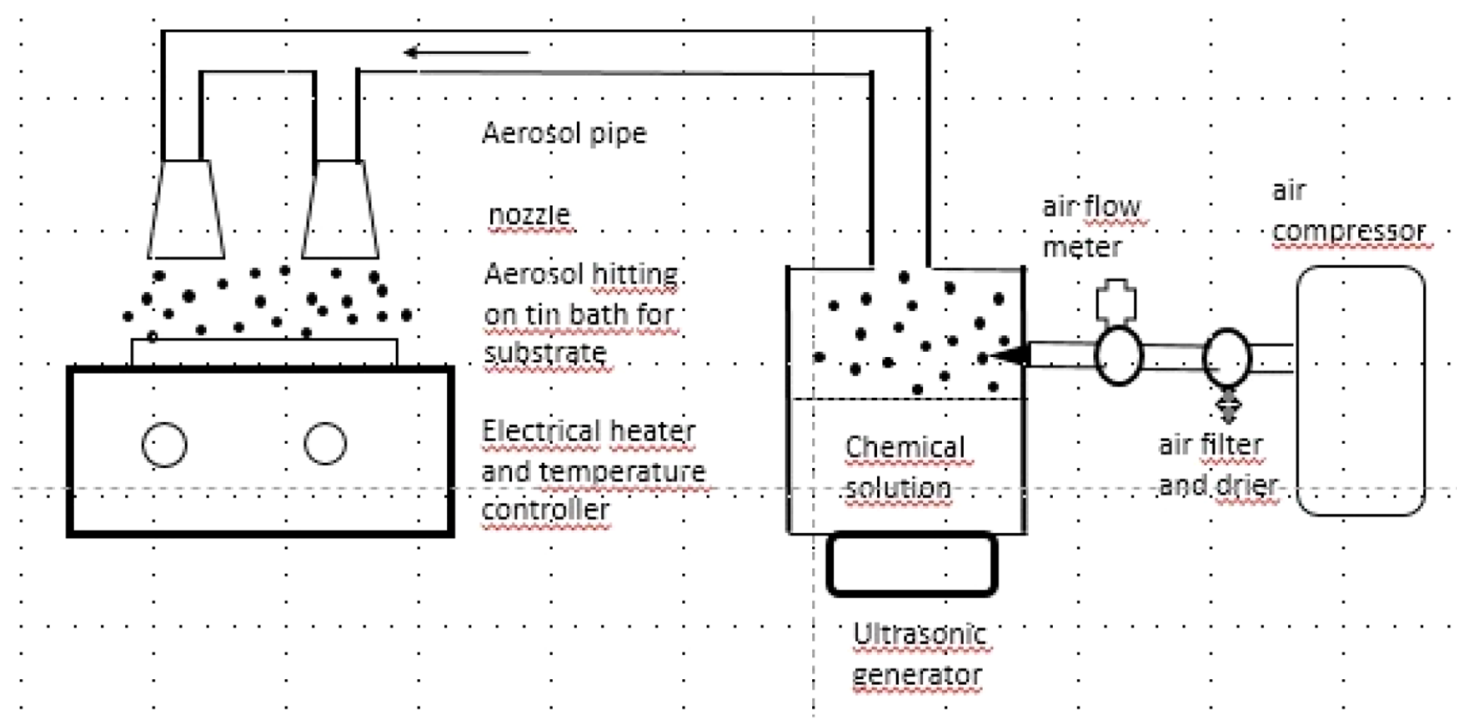

Fig. 2. Mains elements of the ultrasonic spray pyrolysis technique used to prepare thin films this work.

were washed with water and detergent, dried in ethanol and then washed again by immersion in hot acetone to remove any fat residues on the surface.

The precursor salts to obtain the iron oxide, $\mathrm{Fe}_{2} \mathrm{O}_{3}$ films contaminated with manganese were iron nitrate, Fe $\left(\mathrm{NO}_{3}\right)_{3} \cdot 6 \mathrm{H}_{2} \mathrm{O}$ (Meyer 97\%) and manganese chloride, $\mathrm{MnCl}_{2} \cdot 4 \mathrm{H}_{2} \mathrm{O}$ (Tecsiquim 98\%). They were dissolved in deionized water at different concentrations. Subsequently, appropriate volumes of the precursors were poured to obtain $100 \mathrm{ml}$ of the solution to be spray. We sprayed the solution for $15 \mathrm{~min}$ at a flow of $5 \mathrm{~L} / \mathrm{min}$, using dry air as the carrying gas. The titanium sheets were placed on a tin bed, and the material was immediately deposited. The deposits were made inside an air hood for allow that the products in gas phase evacuate and not interfere with the reaction. We found that this procedure is superior to others described in the literature, making more efficient deposits and obtaining improve optical responses in the prepared black coating material.

After each sample was obtained, it was then subjected to a heat treatment for two hours to stabilize the phase. The coatings were heated from $350{ }^{\circ} \mathrm{C}$ up to $600^{\circ} \mathrm{C}$, at $50^{\circ} \mathrm{C}$ intervals, by using a Thermolyne electrical oven.

Subsequently, we analyzed the structural, optical, and morphological characteristics. A Varian Cary 5E UV-VIS spectrophotometer with an integration sphere to measure the spectral total reflectance spectra of the samples, was used. This measurement was utilized to calculate the total solar absorptance of the samples (by means the integration of the reflectance spectrum in the solar range, Eq. (1)). To determine the thermal emittance coefficient, we evaluate an arithmetic average of the difference (100\%-spectral reflectance \%) in the infrared region, equation (2). These spectra were measured with an IR spectrophotometer with FTIR Fourier transform from Thermo Scientific, model IS50 FT-IR. Theoretically solar absorptance is defined as the fraction between absorbed radiation and incident solar radiation emulated from the spectrophotometer incident film. It was calculated according to equation (1), where $\lambda$ is wavelength, $\mathrm{R}(\lambda)$ reflectance and Is $(\lambda)$ solar normal irradiance.

$$
\alpha_{S}=\frac{\int_{0.3}^{2.5} I_{S}(\lambda)(1-R(\lambda)) d \lambda}{\int_{0.3}^{2.5} I_{s}(\lambda) d \lambda}
$$

The thermal emittance is a ratio between a radiation emitted by the surface and the radiation that a black body at the same temperature emit, which is presented as:

$$
\varepsilon_{T}=\frac{\int_{2.5}^{25} E(\lambda, T)(1-R(\lambda)) d \lambda}{\int_{2.5}^{25} E(\lambda, T) d \lambda}
$$

where $\mathrm{E}(\lambda, T)$ is the spectrum of the radiation of a blackbody at temperature $\mathrm{T}$ [4].

For the surface profilometry analysis, a Stylus profilometer Bruker Dektak XT sweep an area around of $1000 \mathrm{~mm}^{2}$, was used. The analysis for the structural characterization of the samples were measured using a Bruker D8 Advance X-ray diffractometer. Reitveld type crystalline refinement, using the Topas software, was used to describe the samples' structural characteristics. Measurements of $\mathrm{TiNO}_{\mathrm{x}}$ 's optical properties, as reference material, was perform on a sample of this commercial material on glass, which is the material used in the manufacture of the evacuated tubes of commercial solar collectors.

\section{Results and discussion}

\subsection{Films preparations}

The experimental process consisted of preparing deposits of Mn-doped $\alpha-\mathrm{Fe}_{2} \mathrm{O}_{3}$ on titanium substrates, for different 
Table 1. Color, appearance, film thickness and optical properties of samples prepared at different temperatures with 0.0015 and $0.0035 \mathrm{~mol} / \mathrm{l}$ concentrations of $\mathrm{Fe}$ and $\mathrm{Mn}$, respectively.

\begin{tabular}{lllll}
\hline Sample & $\begin{array}{l}\text { Preparation } \\
\text { temperature }\left({ }^{\circ} \mathrm{C}\right)\end{array}$ & $\begin{array}{l}\text { Color and } \\
\text { homogeneity }\end{array}$ & $\begin{array}{l}\text { Film thickness, } \\
\text { in microns }\end{array}$ & $\begin{array}{l}\text { Solar absorptance } \\
\text { and emittance }\end{array}$ \\
\hline (a) & 350 & Reddish, uniform & 1.011 & $0.75 ; 0.03$ \\
(b) & 400 & Reddish, uniform & 0.749 & $0.76 ; 0.04$ \\
(c) & 450 & Reddish, uniform & 1.170 & $0.89 ; 0.05$ \\
(d) & 500 & Dark reddish, uniform & 1.008 & $0.78 ; 05$ \\
(e) & 600 & Black, uniform & 0.450 & $0.94 ; 0.07$ \\
\hline
\end{tabular}

Table 2. Ssolar absorptance values of $\mathrm{Mn}$-doped $a-\mathrm{Fe}_{2} \mathrm{O}_{3}$ films deposited on titanium substrate at $600{ }^{\circ} \mathrm{C}$ by ultrasonic spray pyrolysis, as a function of the concentrationof $\mathrm{Fe}$ and $\mathrm{Mn}$.

\begin{tabular}{llll}
\hline Sample & {$[\mathrm{Fe}] \mathrm{mol} / \mathrm{lt}$} & {$[\mathrm{Mn}] \mathrm{mol} / \mathrm{lt}$} & Solar absorptance \\
\hline (a) & 0.0015 & 0.0035 & 0.943 \\
(b) & 0.025 & 0.0025 & 0.771 \\
(c) & 0.02 & 0.003 & 0.697 \\
(d) & 0.015 & 0.0035 & 0.755 \\
(e) & 0.01 & 0.004 & 0.692 \\
(f) & 0.05 & 0.0045 & 0.722 \\
\hline
\end{tabular}

concentrations of $\mathrm{Fe}$ and $\mathrm{Mn}$ ions in the spray solution and heated at different temperatures. The resulting films exhibit a good color, uniformity and the best solar optical properties. The pyrolysis chemical reaction of the precursor substances at temperatures greater than $350^{\circ} \mathrm{C}$ could be proposed as:

$$
\begin{aligned}
\mathrm{Fe}\left(\mathrm{NO}_{3}\right)_{3} \cdot 6 \mathrm{H}_{2} \mathrm{O} & +\mathrm{MnCl}_{2} \cdot 4 \mathrm{H}_{2} \mathrm{O} \stackrel{\mathrm{H}_{2} \mathrm{O}}{\longrightarrow} \alpha-\mathrm{Fe}_{2} \mathrm{O}_{3}: \mathrm{Mn} \\
& +\mathrm{HCl}+\mathrm{HNO}_{3}+\mathrm{H}_{2} \mathrm{O}
\end{aligned}
$$

where, as result of the thermal decomposition, Mn-doped $\alpha-\mathrm{Fe}_{2} \mathrm{O}_{3}$ is obtained as well as the products $\mathrm{HCl}, \mathrm{HNO}_{3}$ and $\mathrm{H}_{2} \mathrm{O}$ in gas phase.

Initially, a visual practical test to understand better how different preparation temperatures modify the appearance of deposit for fixed concentrations of Fe and $\mathrm{Mn}$ was realized. Also, the roughness and solar optical properties of the films for fixed concentrations of $\mathrm{Fe}$ and $\mathrm{Mn}$ at 0.0015 and $0.0035 \mathrm{~mol} / \mathrm{l}$, respectively are showed in Table 1.

The best samples with a dark color and homogeneous finish were yield at $600{ }^{\circ} \mathrm{C}$. The sample thicknesses exhibit a maximum at $450{ }^{\circ} \mathrm{C}$ and tends to decrease as a function of the increasing temperature, reaching a thin film thickness around one half micron for a temperature of $600^{\circ} \mathrm{C}$, as shown in Table 1.

\subsection{Spectral reflectance results}

For each of these samples (Tab. 1), spectral reflectance measurements were carried out to determine the value of the optical properties: solar absorptance and thermal emittance. After obtaining these values, they were compared with each other to find the temperature that optimizes the best optical properties. Analyzing and observing the samples' finishes showed that $600{ }^{\circ} \mathrm{C}$ is the temperature that offer the best optical properties (high absorbance and low emittance).

Once this parameter was established, another variation was made, this time in the different molar compositions of the solution to be deposited on the substrates, in order to investigate the best composition to optimize the optical properties. Table 2 shows the values of the absorptance estimated in the solar spectrum for different concentrations of the precursor salts. Figure 3 shows the spectral reflectance behaviors for some representative thin films of Mn-doped $\alpha-\mathrm{Fe}_{2} \mathrm{O}_{3}$ on titanium substrates samples deposited at $600{ }^{\circ} \mathrm{C}$ related to the concentrations indicated in Table 2.

The experiments described above were carried out at $600^{\circ} \mathrm{C}$, and the variations of the $\mathrm{Fe}$ and $\mathrm{Mn}$ ions were the variable modified, according to the Table 2 . We highlight that sample (a) yielded the highest value of solar absorptance (94\%), at levels comparable to the commercial one, TiNOx [4]. The other samples from (b) to (f) present that parameter below $80 \%$, and are therefore not viable for possible commercial applications.

Figure 4 shows the reflectance of the sample prepared with 0.0015 and $0.0035 \mathrm{~mol} / \mathrm{l}$ concentrations of $\mathrm{Fe}$ and $\mathrm{Mn}$, respectively, at 450 y $600{ }^{\circ} \mathrm{C}$. The results suggest that the preparation temperatures modify the optical properties trough the spectral reflectance in the $\mathrm{uV}$-Vis-NIR region. We also compared TiNOx and Mn-doped $\alpha-\mathrm{Fe}_{2} \mathrm{O}_{3}$ using the concentration associated to the sample a), in Table 2. A deviation around of $3 \%$ was found between the absorptance 


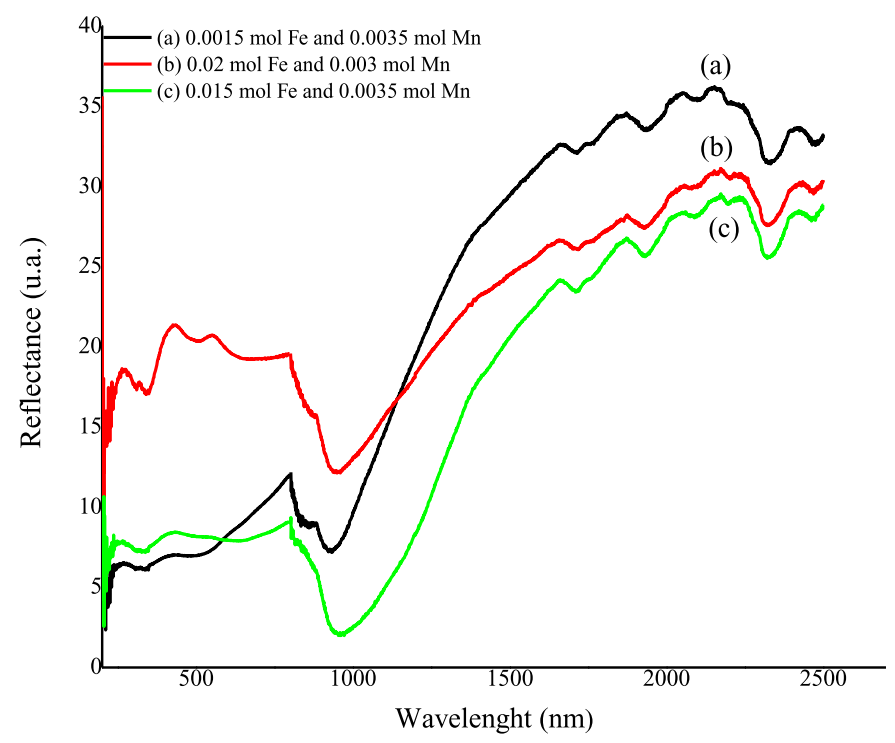

Fig. 3. Spectral reflectance in the solar spectrum, for representative samples prepared at different concentrations of Fe and $\mathrm{Mn}$, $\mathrm{mol} / \mathrm{l}$, respectively (a) 0.0015:0.0035, (b) 0.02:0.003, (c) 0.015:0.0035. Samples heat-treated at $600{ }^{\circ} \mathrm{C}$ in air atmosphere.

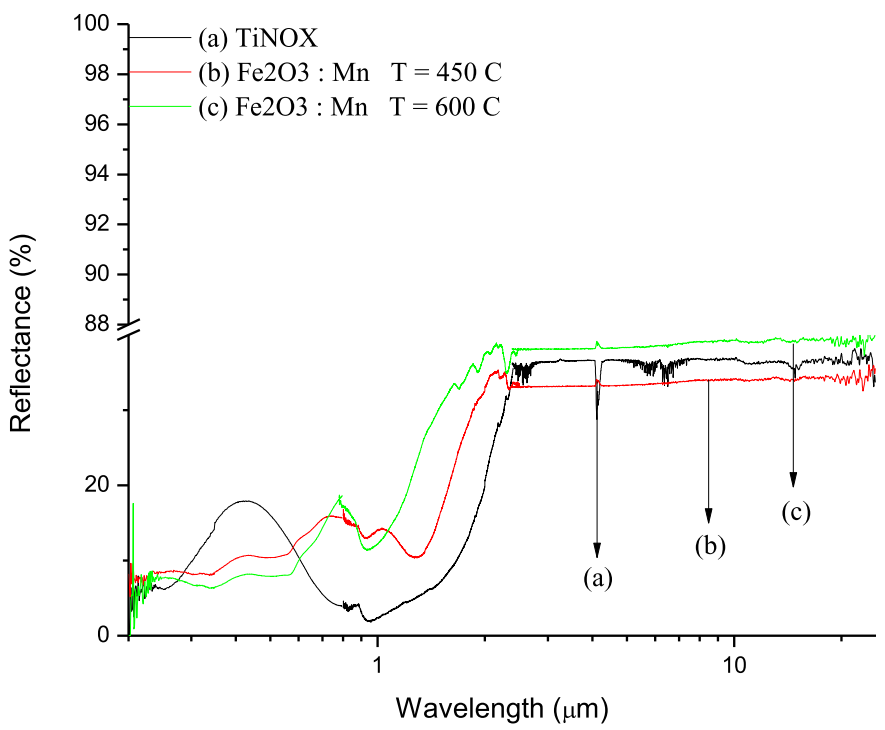

Fig. 4. Total spectral reflectance (\%) in the entire solar and IR spectral region for (a) commercial TiNOxsample and (b) and (c) some of our representative samples, which let us evaluate optical properties.

values of the material obtained employing the ultrasonic spray pyrolysis technique and the commercial TiNOx absorber. This low deviation demonstrates that spray pyrolysis is an excellent procedure for obtaining solar absorbers. Also, the experimentally-obtained emittance values shown in Table 2 are comparable to those reported for the $\mathrm{TiNO}_{\mathrm{x}}$ absorber.

The uncertainty of a digital measuring device is the resolution, that is, the smallest subdivision given on the
Table 3. Diffraction planes for Ti, according to the PDF standards used to define peaks.

\begin{tabular}{lll}
\hline Angle $\left({ }^{\circ}\right)$ & Diffraction planes & Crystal size $(\mathrm{A})$ \\
\hline 35.09 & $(100)$ & 815.1 \\
38.42 & $(002)$ & 844.3 \\
40.17 & $(101)$ & 1599.4 \\
53.00 & $(102)$ & 835.6 \\
62.94 & $(110)$ & 533.6 \\
\hline
\end{tabular}

reflectance measuring device, that in our case reach $0.01 \%$ of the reflectance value. That led us to have a low uncertainty in the solar optical properties evaluation this work.

Our results are interesting: pyrolytic spray technique yields a homogeneous and stable film of the material and the values of solar absorptance and the thermal emittance are comparable with the commercial material $\mathrm{TiNO}_{\mathrm{x}}$. The ultrasonic spray pyrolysis reaction process is an example of a chemical vapor deposition (CVD); this deposition method's principal advantage is that it provides a homogeneous deposit on the titanium substrate. The homogeneity provided by the ultrasonic pyrolytic spray technique is essential for Mn-doped $\alpha-\mathrm{Fe}_{2} \mathrm{O}_{3}$ to be used as a solar coating with potentially commercial range in solar collectors.

As noted above, the material studied in this work is comparable with the commercial absorber $\mathrm{TiNO}_{\mathrm{x}}$ in terms of the similarly optical properties for the photo-thermal conversion. As mentioned in the beginning, Mn-doped $\alpha-\mathrm{Fe}_{2} \mathrm{O}_{3}$ has been obtained by simple techniques; however, the solar optical properties values were slightly deficient compared with the $\mathrm{TiNO}_{\mathrm{x}}$ ones. The technique used here lead to optical good quality of the absorber films; therefore these new materials may be used to manufacture solar panels for finned tube solar collectors, probably at less cost that the required to obtain $\mathrm{TiNO}_{\mathrm{x}}$.

\subsection{XRD and rietveld results}

Figure 5 shows the X-ray diffraction pattern for the optimized Mn-doped $\alpha$ - $\mathrm{Fe}_{2} \mathrm{O}_{3} / \mathrm{Ti}$ sample prepared to different temperatures. The diffraction pattern at $350{ }^{\circ} \mathrm{C}$ is clearly defined; as the temperature increases, the intensities of the peaks increase as a direct consequence of higher crystallization of Mn-doped $\alpha \mathrm{Fe}_{2} \mathrm{O}_{3}$.

It was found that the hematite phase was kept in all samples, and the only change that occurred was that the peaks of x-ray diffraction became more pronounced increasing the temperature. This sharpening of the peaks explains a high level of crystallinity, which is congruent given the fact that an increase in temperature brings about better crystalline ordering, and therefore more pronounced peaks. The thermal treatment of the prepared material, let to the thin film increase its density and improves their optical properties. Tables 3 and 4 show the values of the diffraction peaks and crystal size for titanium as substrate and hematite as the absorber phase. 
A Rietveld analysis using data from the difractogram in Figure 5 at concentrations of Fe and $\mathrm{Mn}$ of 0.0015 and $0.0035 \mathrm{~mol} / \mathrm{lt}$, respectively was carried out. The experimental data is in agreement with theoretical projections, as shown in the curve adjustment Figure 6.

Table 4. Diffraction planes for hematite.

\begin{tabular}{lll}
\hline Angle $\left(^{\circ}\right)$ & Diffraction planes & Crystal size $(\mathrm{A})$ \\
\hline 24.29 & $(012)$ & 653.4 \\
33.15 & $(104)$ & 797.4 \\
35.61 & $(110)$ & 527.9 \\
49.47 & $(024)$ & 637.4 \\
54.08 & $(116)$ & 810.8 \\
\hline
\end{tabular}

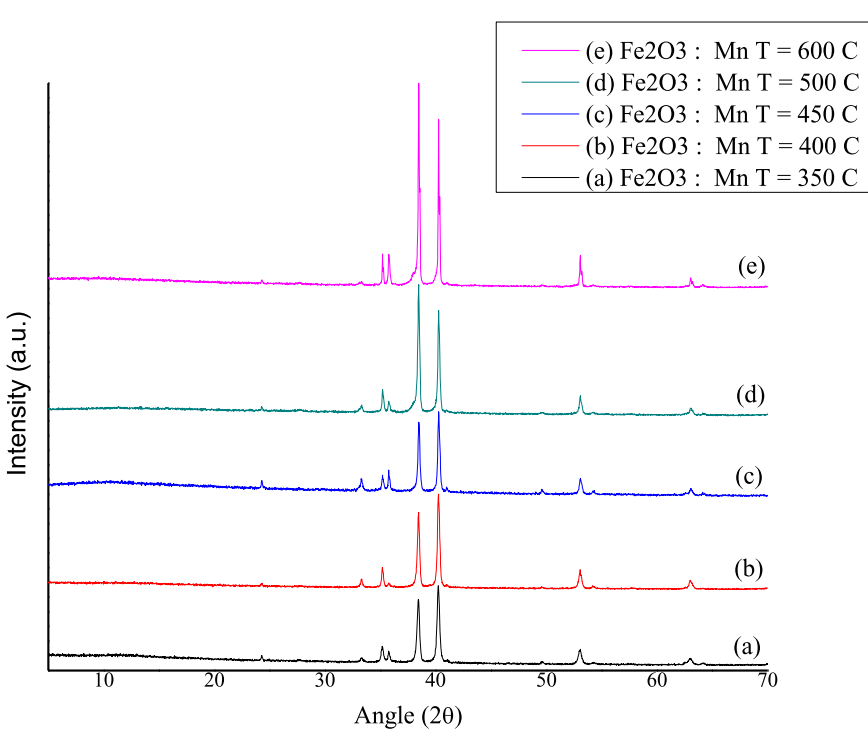

Fig. 5. X-ray diffractogramof $\mathrm{Mn}$ doped $\mathrm{Fe}_{2} \mathrm{O}_{3} / \mathrm{Ti}$ samplesat different temperatures.
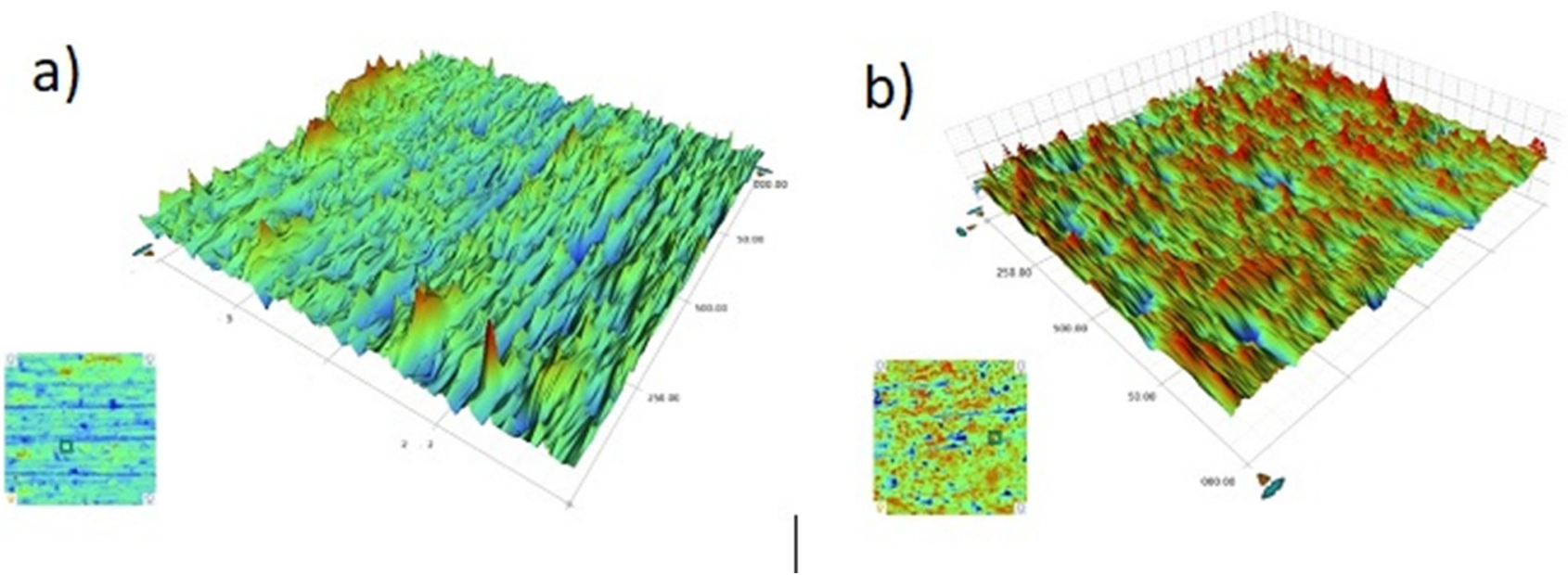

Fig. 7. Surface roughness of $\mathrm{Fe}_{2} \mathrm{O}_{3}$ : $\mathrm{Mn}$, (a) $450{ }^{\circ} \mathrm{C}(0.117 \mu \mathrm{m})$ and (b) $600{ }^{\circ} \mathrm{C}(0.045 \mu \mathrm{m})$.
Figure 7 corresponds, to samples prepared with the concentrations of $\mathrm{Fe}$ and $\mathrm{Mn}$ that optimize the solar absorptance. The analysis of the roughness was performed to understand the material's texture changes as temperature increases. In fact, as the temperature treatment increases, the surface roughness decrease significantly, probably by the increase in the material density.

\section{Conclusions}

This work shows that the ultrasonic spray pyrolysis technique is suitable for depositing thin films solar absorber of $\mathrm{Mn}$-doped $\alpha-\mathrm{Fe}_{2} \mathrm{O}_{3}$ on titanium substrate. The molar concentration of $\mathrm{Fe}$ and $\mathrm{Mn}$ to obtain thin films having

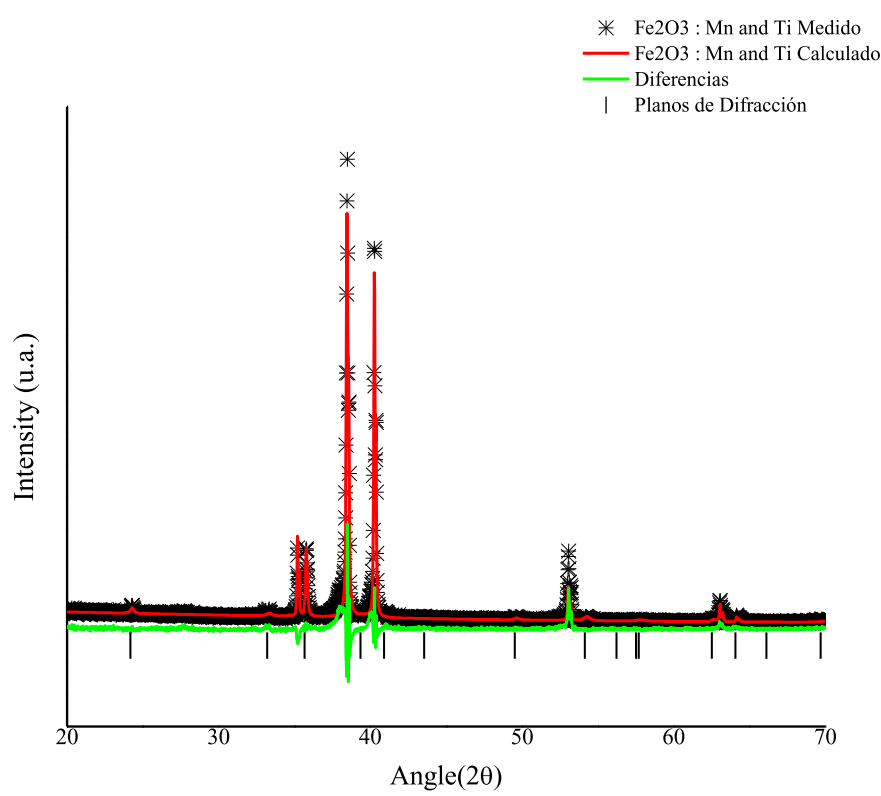

Fig. 6. Rietveld adjustment forMn doped $\mathrm{Fe}_{2} \mathrm{O}_{3}$ for a solution concentration of $\mathrm{Fe}$ in $0.0015 \mathrm{~mol} / \mathrm{lt}$ and $\mathrm{Mn}$ in $0.0035 \mathrm{~mol} / \mathrm{lt}$ deposited on titanium plates. 
high solar absorptance (0.94) and low thermal emittance (0.07) was 0.0015 and $0.0035 \mathrm{~mol} / 1$, respectively. The optical properties values for the thin films are close to those of the reference TiNOx, which is used commercially as an absorber coating.

$\mathrm{X}$-ray diffraction analysis indicates that our technique guarantees reach the hematite phase, a fundamental element for strong optical absorption. The Rietveld refinement confirms that the titanium phase, as well as the hematite phase, are present. Therefore, the optical properties response seems to be due to the contribution of the total chemical phases present in the surface, measured by XRD analysis.

Concerning the optical properties, the reflectance spectra measured and shown in this work allow us to appreciate the potential good solar absorber selectivity of $\mathrm{Mn}$-doped $\alpha-\mathrm{Fe}_{2} \mathrm{O}_{3}$. The relatively simple technique can be considered as an option for the production of this material to deposit in large areas, as is required by manufacturers of solar collectors.

\section{References}

1. D. Atasi, B. Bikramjit, Energy saving coating materials, Elsevier Amsterdam, 133 (2020)

2. E.L. Unger, Curr. Opin. Green Sustain. Chem. 4, 72-76 (2017)

3. C.E. Kennedy, Review of Mid- to High- Temperature Solar Selective Absorber Materials, NRELTP-520- 31367, (2002)

4. Q. Yuan et al., Chem. Mater. 29, 23 (2017)

5. Ch. Zhonghua, T. Boström, Renew. Energy Environ. Sustain. 11, 1-6 (2016)
6. J. Chen, L. Xu, L. Li, X. Gou, Adv. Mater. 17, 582-586 (2005)

7. S. Kumari, P. Singh, C. Tripathi, Int. J. Photo. 6, 1-6 (2007)

8. M. Huang, W. Chang, J.C. Lin, J. Alloys Compd. 636, 176-182 (2015)

9. C. Park, J. Walker, R. Tannenbaum, Appl. Mater. Interfaces 1, 1843-1846 (2009)

10. J. Glasscock, P. Barnes, I. Plumb, J. Phys. Chem. 111, 477-488 (2007)

11. C.S. Gurudayal, S. Chiam, M. Kumar, Appl. Mater. Interfaces 6, 5852-5859 (2014)

12. P. Liao, E.A. Carter, J. Appl. Phys. 112, 013701-1-013701$13(2012)$

13. B.A. Balko, K.M. Clarkson, J. Electrochem. Soc. 148, E85-E91 (2001)

14. F. Achouri, S. Corbels, L. Balan, J. Phys Chem. Sol. 75, 10 (2014)

15. R. Ullah, J. Dutta, J. Hazard. Mater. 156, 194-200 (2008)

16. K. Rekha, M. Nirmala, M. Nair, Physica B 405, 3180-3185 (2010)

17. M. Mahmood, S. Baruah, Mater. Chem. Phys. 130, 531-535 (2011)

18. D. Zhang, Russ. J. Phys. Chem. A 86, 93-99 (2012)

19. Y. Yang, Y. Li, L. Zhu, Nanoscale 5, 10461-10471 (2013)

20. R. Saleh, N. Djaja, Spectrochim. Acta A 130, 581-590 (2014)

21. K. Umar, A. Aris, T. Parveen, Appl. Catal. A Gen. 505, 507-514 (2015)

22. M. Wan, P. Wong, R. Hussin, J. Alloy Compd. 59, 39-45 (2014)

23. M. Kawano, H. Takebe, M. Kuwabara, Opt. Mater. 32, 277-280 (2009)

Cite this article as: Carlos David Hernández-Pérez, Enrique Barrera-Calva, Federico González, Victor Rentería Tapia, Ultrasonic spray pyrolysis technique to generate a solar absorber coating of Mn-doped $\alpha-\mathrm{Fe}_{2} \mathrm{O}_{3}$, Renew. Energy Environ. Sustain. 6, $3(2021)$ 